\title{
DIE GRENZEN
}

\section{GEISTIGER GESUNDHEIT UND KRANKHEIT.}

\author{
REDE, \\ GEHALTEN ZUI: FEIER DES GLBUR'TSTIGES \\ SR. MAJESTÄT DES KÖNIGS ALBERT VON SACHSEN \\ AM 23. APRIL 1896 \\ voN
}

DR. PAUL FLECHSIG,

o. Ö. PROFESSOR DER PSYCHIATRE.

ZW LITYR UNVERÄNDHTTER ABDRUCK.

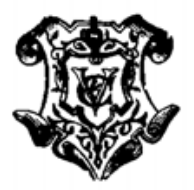

LEIPZIG,

VERLAG VON VEIT \& COMP.

1896. 
Druck von Metzger \& Wittig in Leipzig. 